\title{
ESRC-DFID Research for Policy and Practice:
} Water security

\section{September 2019}

\section{Foreword}

A ccess to clean water is essential for life and yet 80 per cent of the world's population live in areas threatened by water insecurity. All too often in water management, short-term gains for the few are prioritised above long-term benefits for the many. This must stop, if we are to deliver on Sustainable Development Goal 6: ensure availability and sustainable management of water and sanitation for all.

Over-allocation, pollution, extreme weather, urbanisation, land degradation, and conflict can all conspire against progress to achieve water security for all. Weak water governance undermines health, livelihoods, and economic opportunity, and consistently, vulnerable people and communities feel the brunt of these impacts.

To effectively address the global water crisis, and the crushing inequalities it reinforces around the world, we need reliable and objective evidence about what is happening. It is essential that we do not isolate water as an issue, and work together with researchers, governments, businesses, and community groups. It is only then that we can access the knowledge needed to forge durable solutions.

The selection of Economic and Social Research Council (ESRC) and Department for International Development (DFID)-funded research that follows, explores the realities facing people for whom water insecurity is a daily threat. Experiences of managing reservoirs in Burkina Faso identifies the challenges and conflicts facing user groups. Meanwhile, in Ethiopia, a study of pastoralists looks at the inter-relationships between emotional wellbeing and water access.

This small snapshot provides useful insights for what is needed to tackle the global water crisis. Central to both projects are collaborative ways of working and iterative dialogues between research and policy communities, water users, and citizens. Working in this way is key to understanding the complexities and discovering new solutions to tackling the world's spiralling water resource challenges.

\section{Dr Nick Hepworth}

Founder and Executive Director of Water Witness International. Working for a world protected against pollution, droughts, floods and resource conflict, and for a fair water future.

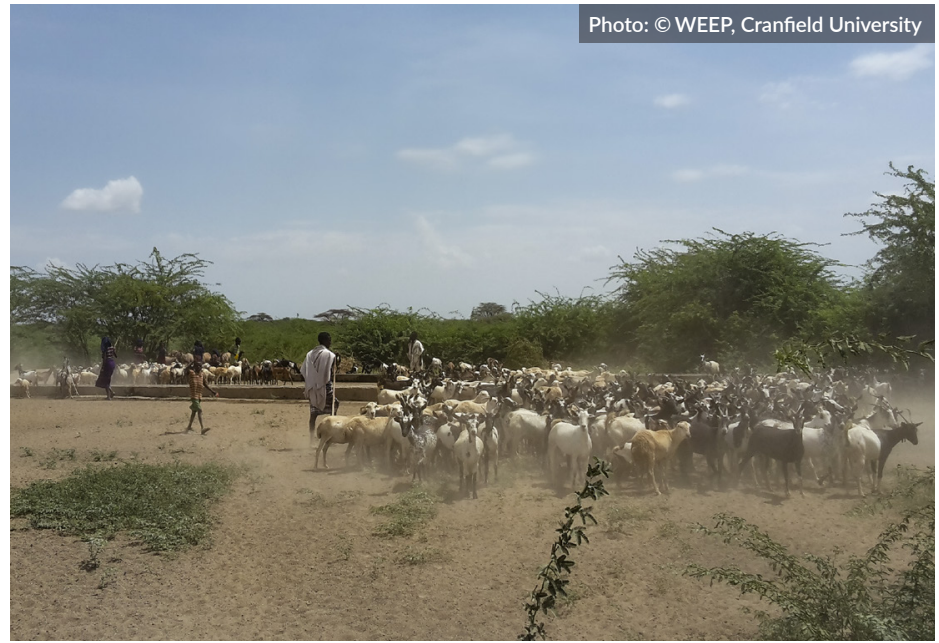

Pastoralists in the Afar Region, Ethiopia.

\section{Key messages}

- Inclusive dialogue is required to ensure representation of the needs of different user groups and to reach a common vision for water management.

- People's own coping strategies, and capacities to innovate and rely on the strength of local networks can contribute to sustainable, real-world solutions.

- People's needs must be better captured in metrics and indicators to address water security concerns.

- Fostering inclusive collective water management and multi-stakeholder 'spaces' among different user groups is important to ensure that conflicted roles are openly discussed, and solutions are contextually relevant.

- It is vital to ensure that the needs of different groups, including pastoralists and other communities with diverse and complex needs in terms of water, are included in a common vision for water management. 


\section{Water scarcity and emotional wellbeing among pastoralists}

Pastoralists (and other communities in general) have diverse and complex needs in terms of water which are not considered in the conventional water security indicators set by the global water community. Measuring emotional wellbeing introduces a broader indicator to embody specific livelihood needs, and to complement conventional indicators for the wider spectrum of the monitoring and evaluation of water provision.

Pastoralism is a distinct livelihood adaptation to living in arid and semi-arid conditions. Centred on livestock production, the key to pastoralism's success is mobility over rangelands, and flexibility in traditional customary rights to cope with climate and other stress factors. However, these strategies have been eroded from pressures such as the re-appropriation of traditional rangelands, enforced settlement into agro-pastoralism, and the changing climate.

These increasing concerns underpin the urgency to provide adequate water infrastructure for pastoralists. However, the use of conventional indicators such as quantity, accessibility, quality, and affordability to assess their needs have demonstrated limitations and failed to account for their distinct livelihood needs around mobility and multiple uses for water. For example, taking into account the water needs of different species of livestock and also domestic uses of water. The primary aim of this project was to develop a new proxy indicator which would capture the broader characteristics of pastoralists. The use of emotion as an indicator and a focus on emotional wellbeing moves beyond conventional measures to capture the inter-subjective, relational dimension which shapes the human experience concerning water.

Research was undertaken among pastoralists in the Afar Region, Ethiopia from December 2017-April 2019. Focus group discussions explored ethno-lingual perceptions of water security and emotion to develop the indicator. A survey was used to test the indicator and measure the impact of water security on emotional wellbeing. Workshops were undertaken with stakeholders to develop and introduce the indicator. Findings revealed that emotional responses closely aligned with seasonality. Pastoralists expressed happiness (ferhi) and extreme happiness (estrahina) with the availability of water in the rainy season. In the dry season, they experienced grief (gemoma), extreme worry (hisabona), and fatigue (tabaqi) because of the long distances travelled for water and the family displacement this caused for both men and women. 'We feel fatigue when travelling long distances or have to dig the river bed for water that is not sufficient for our needs.' (Male pastoralists, focus group discussion).

Insights from this research presented the benefits for pastoralist communities in the Afar Region and in the wider context:

- Findings presented an emotional profile to frame local water initiatives and other development interventions for pastoralists in the target community, and a culturally sensitive indicator readily available to use in other Afar communities.

- Interactive workshops with stakeholders presented an additional tool to complement conventional measures to reveal patterns of vulnerability and relationships with water.

- The emotion indicator can be implemented in many diverse contexts and fields. Having the flexibility to measure emotional wellbeing contributes to the growing consensus that measures of subjective wellbeing are increasingly seen as having more or equal validity in assessing standards of living over current measures of gross domestic product (GDP).

Measuring emotion also has distinct advantages for wider development initiatives such as climate resilience and health projects. Persistent negative emotions can lead to mental health conditions such as anxiety and depression, which in turn reduces the ability to cope and adapt to climate stressors.

This study has shifted progress in this field to deliver a new, unique perspective to assess water security through an indicator designed to measure emotion to provide a more human focus to the monitoring and evaluation process. The emotion indicator complements the conventional measures of water security by not only reinforcing their results as a proxy measure but also by providing a broader perspective of water security, with emotions serving to further highlight aspects of water security which need attention. Significantly palpable benefits of the tool are its adaptability for different contexts, its transdisciplinary application in other fields, and its versatility in design. It also has potential as an important role within other development agendas such as the assessment of poverty, food security, and livelihoods, and other disciplines such as health. Key implications of the study show that:

- Negative emotions associated with water security could indicate mental health issues, with the use of the emotion indicator as integral in detecting 'trigger' points.

- Emotion serves to highlight the more human aspects of monitoring and evaluation to serve as an entry point to gain a more holistic understanding of the context.

- This tool can be adapted to any context, taking into account the inherent cultural identity of different communities.

Project title: Water Security in Ethiopia and Emotional Response of Pastoralists (WEEP)

\section{Principal Investigator: Paul Hutchings}

Lecturer in Water, Sanitation and Hygiene (WASH) Impact Evaluation, Cranfield University.

Lead organisation: Cranfield University.

Partners: IRC Ethiopia, Oxfam Ethiopia, International Water Management Institute, and Friendship Support Association. 


\section{Engaging communities for sustainable water management in Burkina Faso}

In seasonally dry areas of Burkina Faso, small reservoirs provide a lifeline for rural communities. Yet, collectively managing these reservoirs for multiple purposes in a sustainable and equitable manner poses critical challenges and can lead to conflicts among user groups. Participatory research shows the promise of innovation platforms (IPs) for fostering inclusive collective water management among socially differentiated users.

Due to extreme rates of sedimentation, ageing, and poor maintenance, reservoirs in Burkina Faso's Boulgou Province, in the centre-east region, are shrinking and tensions are rising as residents experience food and income insecurity. The multiple uses of Boulgou's small reservoirs increasingly fuels disagreements in years when water supplies are insufficient to meet demand. Competition over the use of reservoir water by different local interest groups, such as Fulani herders, Bissa fishers, and Mossi and Bissa agriculturalists, brings with it conflicts of interest that are largely overlooked by local water authorities. Institutions regulating water use and land management in reservoir catchment areas and irrigation zones have not kept pace with rapid rural changes and reservoir developments, leading to inadequate management of this resource.

To address these challenges, participatory research on 'Pathways Out of Poverty for Burkina Faso's Reservoir-Dependent Communities' was conducted in two of Boulgou's small reservoirs from February 2018May 2019. A multidisciplinary team from Bioversity International, SNV World Burkina Faso, Université de Ouagadougou, and King's College London convened local communities, civil society organisations (CSOs) and non-governmental organisations (NGOs), and governmental extension services from several sectors (water, agriculture, livestock). These actors interacted in IPs designed to foster dialogue and collective action for sustainable and equitable reservoir management. IPs are multi-stakeholder participatory 'spaces' that bring together actors with shared interests in a specific area to negotiate and develop innovations. The platforms convened in this project aimed to develop a collective vision for reservoir management.

Participants began by identifying the root causes of degradation of their reservoir, with attention to the role different user groups played, and possible solutions. They prioritised solutions based on feasibility, prospective impacts on social equity and cohesion, economic returns, and ecological outcomes. Participants then detailed and costed out the top-ranked solutions, and developed action plans.

During a series of four meetings, participants moved through several phases of reflection and dialogue. Local water user representatives (agriculturalists, horticulturalists, fishers, and herders) actively participated in these meetings. Participants worked in gender- and age-segregated sub-groups, and fed back discussions in plenary, enabling a wider dialogue to take place. Government actors as well as NGO and CSO participants formed their own sub-group and engaged in plenary discussions. The process of working in this way brought together socially differentiated participants, permitting a sharing of perspectives and the fostering of mutually agreeable solutions.

As a result, women, who had previously been excluded from water management committees, became increasingly vocal as they, and other platform participants, recognised the important role they had to play in reservoir management and governance. Relations between community members and government extension agents were strengthened. Local communities in one reservoir appropriated reservoir management processes. These included collective efforts to unblock a main water channel, and outreach to local government agents. In the other reservoir, historically rooted political disagreements among local leaders hindered collective action. Mediation by the research team resulted in some steps forward, as community members agreed to implement common actions such as placing gabion baskets in the periphery of their reservoir, developing consultation frameworks, and drawing up terms of reference for their local water user committee.

The research provides insights for enabling the resolution of conflicts related to the management of small reservoirs and demonstrates the value of using IPs. It offers strategies for nurturing inclusive, sustainable collective action, not only in water management, but also with respect to other common property resources (CPRs), such as pastures and forests. Insights include:

- Fostering collective action for CPR management requires strategic investments in dialogue among users to generate a common vision;

- Inclusive dialogue requires representation of different user groups - based on gender, generation, location of residence around the reservoir (upstream or downstream), and livelihood strategy - as well as inter-sectoral collaboration;

- IPs that convene socially differentiated stakeholders with neutral facilitation, represent spaces where inclusive dialogue can occur;

- Recognizing the contextual specificities that influence innovation platform dynamics is essential to fostering inclusive dialogue among participants;

- Processes of self-identification of problems and of the development of action plans fosters local appropriation of CPR management with sustainable impacts;

- Such processes should be embedded in efforts to accompany communities in the equitable management of their water resources.

Project title: Pathways out of Poverty for Burkina Faso's ReservoirDependent Communities

\section{Principal Investigator: Marlène Elias}

Bioversity International Gender Specialist, Conservation and Management of Forest Genetic Resources, Bioversity International.

\section{SEE ALSO:}

Benson, V. (2019) Communities Improve Water Management in Burkina Faso, The Impact Initiative

Elias, M. (2019) A Fair Share of Village Water, Economic and Social Research Council (ESRC) blog, 26 April

Elias, M. et al. (2018) 'Pathways out of Poverty for Burkina Faso's Reservoir-Dependent
Communities', presented at the Power of Partnership Conference, Delhi, 5 December

Jones, S.; Elias, M. and Boundaogo, M. (2018) Searching for Pathways towards Equitable and Sustainable Reservoir Management, Bioversity International, 27 February

Pathways out of Poverty for Reservoir-dependent Communities in Burkina Faso (POP-BF) (2019) https://sites.google.com/view/pop-bf 


\section{THE IMPACT INITIATIVE}

For International Development Research

This summary highlights the key messages from research focusing on water security from the ESRC-DFID Joint Fund for Poverty Alleviation and is an output of the Impact Initiative for International Development Research.

It is written in collaboration with research teams and edited by Kelly Shephard, Head of Knowledge, Impact and Policy at the Institute of Development Studies (IDS). The academic reviewer for this paper was Jeremy Allouche, Research Fellow, IDS.

The Impact Initiative seeks to connect policymakers and practitioners with the world-class social science research supported by the ESRC-DFID Strategic Partnership, maximising the uptake and impact of research from: (i) the Joint Fund for Poverty Alleviation Research; and (ii) the Raising Learning Outcomes in Education Systems Research Programme. We seek to identify synergies between these programmes and their grant-holders, support them to exploit influencing and engagement opportunities and facilitate mutual learning. The Impact Initiative is a collaboration between the Institute of Development Studies and the University of Cambridge's Research for Equitable Access and Learning (REAL) Centre.

Email: info@theimpactinitiative.net

Website: www.theimpactinitiative.net

y @the_Impact_Init \#impactlessons

All content is available under the Open Government License v3.0, except where otherwise stated

Joint Fund for Poverty Alleviation: aims to enhance the quality and impact of social science research, addressing the key international development goal of reducing poverty amongst the poorest countries and peoples of the world.

Raising Learning Outcomes in Education Systems Programme: aims to provide policymakers and practitioners with concrete ideas on how to improve

learning outcomes and to inform relevant policy and programme decision.

$\mathrm{E} \cdot \mathrm{S} \cdot \mathrm{R} \cdot \mathrm{C}$ ECONOMIC \& SOCIAL RESEARCH C OUN C I L

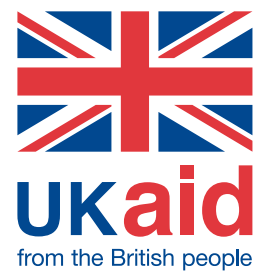

from the British people 